\title{
TRATAMENTO FOTOQUÍMICO DE PERCOLADO DE ATERRO SANITÁRIO
}

\section{PHOTOCHEMICAL TREATMENT OF LANDFILL LEACHATE}

\author{
Núbia Natália de Brito ${ }^{1}$, José Euclides S. Paterniani ${ }^{2}$, Giovani A. Brota ${ }^{3}$, Ronaldo T. Pelegrini ${ }^{4}$ \\ Recebido em 28 de julho de 2010; recebido para revisão em 29 de julho de 2010; aceito em 16 de setembro de 2010; \\ disponível on-line em 11 de outubro de 2010
}

\section{PALAVRAS CHAVES:}

Fotocatálise;

Percolado;

Aterro Sanitário.

\begin{abstract}
RESUMO: Este trabalho teve como objetivo estudar um sistema de tratamento fotocatalítico para o percolado proveniente do aterro sanitário da cidade de Limeira-SP. O sistema consistiu em um tratamento fotocatalítico utilizando $\mathrm{H}_{2} \mathrm{O}_{2} / \mathrm{TiO}_{2}$ com radiação na faixa do visível, realizado em um reator de vidro Pyrex com capacidade volumétrica de 1,7 L (com dimensões de: $100 \mathrm{~mm}$ de diâmetro interno, $145 \mathrm{~mm}$ de diâmetro externo e altura total de $300 \mathrm{~mm}$ ) equipado com refrigeração à água e sistema de recirculação interna do percolado. Após algumas otimizações verificou-se que a máxima eficiência na redução de cor (87\%) foi na condição experimental: volume de $\mathrm{H}_{2} \mathrm{O}_{2} 35 \mathrm{~mL}$ (concentração: $205 \mathrm{mg} \cdot \mathrm{L}^{-1} \mathrm{H}_{2} \mathrm{O}_{2}$ ) adicionados ao reator em alíquotas de $15 \mathrm{~mL}$ (início); $10 \mathrm{~mL}$ (30 minutos) e $10 \mathrm{~mL}$ (60 minutos), concentração de $\mathrm{TiO}_{2} 700 \mathrm{mg} \cdot \mathrm{L}^{-1}$, temperatura $45^{\circ} \mathrm{C}$, vazão de ar de 15 L. $\min ^{-1}$, radiação na faixa do visível e tempo de tratamento de 180 minutos. Tratase de um resultado bastante promissor, principalmente levando-se em consideração a elevada resistência da matriz em estudo.
\end{abstract}

* Contato com os autores:

${ }^{1}$ e-mail : nubiabrito@quimica.ufg.br (N. N. Brito)

Professora Dra. Instituto de Química - Universidade Federal de Goiás

22e-mail : pater@feagri.unicamp.br (J.E. S. Paterniani)

Professor Dr. Livre Docente - FEAGRI - UNICAMP

${ }^{3}$ e-mail : (G. A. Brota)

Tecnólogo em Saneamento Ambiental - FEAGRI - UNICAMP

${ }^{4}$ e-mail : pelegrini@cca.ufscar.br (R. T. Pelegrini)

Professor PhD. Centro de Ciências Agrárias - UFSCAR

ISSN: 0000-0000 (em processo de registro)

(C) 2010 REEC - Todos os direitos reservados.

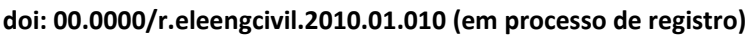

\section{INTRODUÇÃO}

A utilização de oxidantes fortes para tratamento e desinfecção de água é antiga. O primeiro trabalho utilizando ozônio como desinfetante foi feito por De Meritens em 1886. Entretanto, somente em 1973, durante o primeiro Simpósio Internacional em Ozônio para tratamento de águas e efluentes foi usada à terminologia "Tecnologias de Oxidação Avançada". Neste trabalho era utilizada a combinação entre ozônio e radiação ultravioleta para oxidar complexos de cianeto. Além disso, Fujishima e Honda (1972), descrevem a oxidação da água em suspensão de $\mathrm{TiO}_{2}$ gerando hidrogênio e oxigênio e, em 1976 foi publicado o primeiro trabalho utilizando fotocatálise heterogênea na degradação de contaminantes, tanto em fase aquosa quanto gasosa (Teixeira e Jardim, 2004).

Processos oxidativos avançados são aqueles em que a principal via reacional é medida por radical hidroxila $(\mathrm{OH})$. Em função de seu elevado poder oxidante $\left(\mathrm{E}_{0}=2,8 \mathrm{~V}\right)$, o radical hidroxila é extremamente reativo, o que faz com que reaja rápida $e$ 
indiscriminadamente com inúmeros substratos orgânicos, promovendo a sua completa degradação ou transformando-os em produtos de maior degradação biológica. A sua elevada reatividade impede a sua estocagem, o que obriga a utilização de sistemas de geração in situ. Existem várias formas de produzir esse radical, sendo os mais extensivamente estudados: fotocatálise heterogênea, processos baseados na reação de Fenton, sistemas do tipo $\mathrm{UV} / \mathrm{H}_{2} \mathrm{O}_{2}$, processos fotoeletroquímicos e processos baseados nas reações com ozônio (Pacheco e Peralta-Zamora, 2004)

Os POA's em associação com processos biológicos convencionais podem resultar em economia e eficiência no tratamento de efluentes. Como já dito anteriormente o princípio do POA consiste na geração de radical hidroxila conforme Equações 1 e 2, capazes de mineralizar poluentes orgânicos a formas não tóxicas, como $\mathrm{CO}_{2}$ e $\mathrm{H}_{2} \mathrm{O}$ (Brito e Paterniani, 2008).

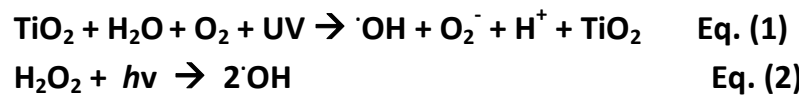

Neste estudo foi realizado o tratamento de percolado de aterro com $\mathrm{TiO}_{2}$ na ausência de radiação, $\mathrm{H}_{2} \mathrm{O}_{2}$ na presença de radiação visível e $\mathrm{TiO}_{2}$ com $\mathrm{H}_{2} \mathrm{O}_{2}$ na presença de radiação visível, a fim de se verificar a máxima eficiência na redução da absorvância.

\section{MATERIAL e MÉTODOS}

Os experimentos foram realizados no Centro Superior de Educação Tecnológica - CESET (UNICAMP), onde foi construído e instalado um reator fotocatalítico para tratamento do percolado pós filtração lenta proveniente do aterro sanitário de Limeira-SP localizado na via Tatuibi $\mathrm{Km} \mathrm{5,5}$, distante $10 \mathrm{Km}$ do centro da cidade. O local é limitado ao norte pelo kartódromo, a leste pelo ribeirão Tatu, ao sul pela Rodovia Municipal de Limeira - Tatuibi, e a oeste pela área de cultivo municipal.

Os laboratórios utilizados para realização das análises foram os laboratórios de físico-química e de tratamento de efluentes.

$O$ aterro sanitário da cidade de Limeira-SP iniciou sua atividade em 1984 (fase I) com características de um lixão e recebia apenas resíduos domésticos até o ano de 1998. Em 1989 iniciaram-se os estudos para implantação de um aterro sanitário, conforme as normas da CETESB. A partir de 1998 iniciou-se a fase II do aterro já com características de um aterro sanitário e preparado para receber resíduos domésticos e resíduos industriais classe IIA não inertes e IIB inertes. A área utilizada atualmente para fase II está em estágio de finalização e uma fase III já está sendo preparada para receber os resíduos sólidos urbanos e industriais apresentando vida útil em média, de 15 anos (GUIZARD, et al., 2004).

Segundo NBR 10.004 (2004), os resíduos classe
IIA não inertes compreendem os resíduos que podem apresentar características de combustibilidade, biodegradabilidade ou solubilidade, com possibilidade de acarretar riscos à saúde ou ao meio ambiente, mas não se enquadram nas classificações de resíduos classe I perigosos. Os resíduos classe IIB inertes são aqueles que por suas características intrínsecas não oferecem riscos à saúde ou ao meio ambiente.

O aterro sanitário de Limeira possui uma área total de aproximadamente $500.000 \mathrm{~m}^{2}$, sendo que $190.000 \mathrm{~m}^{2}$ são destinados para a disposição dos resíduos domésticos e resíduos industriais classe IIA não inertes e IIB inertes Diariamente são gerados cerca de 53 a $85 \mathrm{~m}^{3} / \mathrm{d}$ de percolado. (GUIZARD et al., 2004).

No aterro sanitário de Limeira o percolado de resíduos é tratado por uma lagoa anaeróbia com dimensões de $30 \times 30 \times 3,5$ metros seguida de uma facultativa com dimensões de 30 x 70 × 1,5 metros. Após o tratamento o percolado é recirculado para a massa de resíduos. A lagoa anaeróbia é responsável pelo tratamento primário da água residuária e é dimensionada para receber cargas orgânicas elevadas, que impedem a existência de oxigênio dissolvido no meio líquido. O aterro dispõe ainda de uma lagoa facultativa que é responsável pelo tratamento secundário do percolado e refere-se à dualidade ambiental característica desse tipo de lagoa: aeróbia na superfície e anaeróbia no fundo. Uma foto do aterro pode ser vista na Figura 1, na qual podem ser visualizadas as duas lagoas de tratamento.

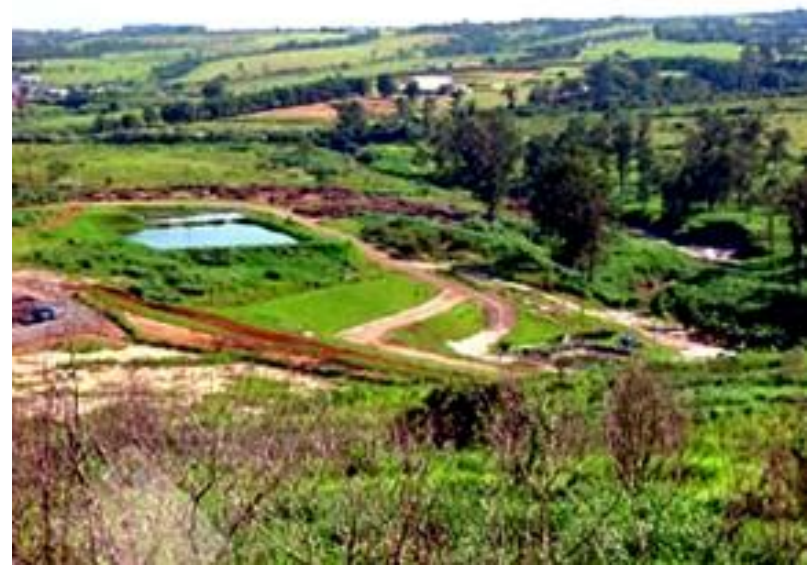

Figura 1: Aterro sanitário de Limeira - SP.

\subsection{Reagentes para o tratamento fotocatalítico}

O semicondutor utilizado no processo fotocatalítico heterogêneo Dióxido de Titânio - Degussa $\mathrm{P} 25\left(\mathrm{TiO}_{2}\right)$.

O peróxido de hidrogênio utilizado no processo fotocatalítico homogêneo foi o da marca Lafan Química Fina, $10 \% \mathrm{~m} / \mathrm{m}$ padronizado por titulação permanganométrica.

\subsection{Tratamento fotocatalítico}

Amostras de percolado para os testes foram coletadas em garrafas de polipropileno e mantidas a 
$4^{\circ} \mathrm{C}$, protegidas da luz. (as amostras foram coletadas de janeiro a junho de 2008 no período vespertino, a amostra de chorume é composta de diversas substâncias tais como: papel, papelão, plástico, vidro, alumínio, metais, tecidos resíduos orgânicos e outros provenientes de resíduos domésticos)

O tratamento fotocatalítico foi realizado em um reator de vidro Pyrex com capacidade volumétrica de 1,7 L (100 mm de diâmetro interno, $145 \mathrm{~mm}$ de diâmetro externo e altura total de $300 \mathrm{~mm}$ ) equipado com refrigeração à água e recirculação do percolado, conforme esquema apresentado na Figura 2.

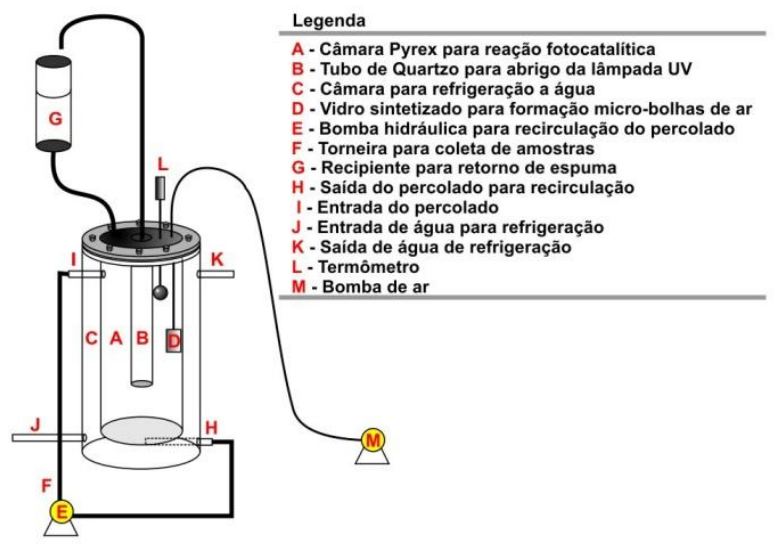

Figura 2: Esquema do reator fotocatalítico.

A fonte de radiação foi provida por uma lâmpada de alta pressão de mercúrio (Philips HPL-N 400 W) pela remoção do bulbo exterior localizado no centro do reator com capacidade para emitir comprimentos de onda na região do UV.

Os experimentos foram processados utilizando refrigeração à água permitindo controlar a temperatura. A agitação do processo foi mantida contínua por meio da recirculação do percolado através de uma bomba hidráulica (Invensys Bav 1115-02U 220 V 60 Hz 34 W). 0 fornecimento de oxigênio para o processo fotocatalítico foi mantido por borbulhamento de ar através de um vidro sinterizado localizado na parte inferior do reator, utilizando para isso um compressor com válvula controladora de vazão (Inalar Compact).

$700 \mathrm{mg} . \mathrm{L}^{-1}$ de $\mathrm{TiO}_{2}$ e $35 \mathrm{~mL}$ de $\mathrm{H}_{2} \mathrm{O}_{2}$ foram adicionadas às amostras de percolado, as quais foram agitadas mediante recirculação e irradiadas em determinados tempos (por otimização). Para o controle analítico, alíquotas foram retiradas em intervalos convenientes e centrifugadas. Em geral o tempo de tratamento fotocatalítico foi suficiente para degradar o peróxido de hidrogênio residual. Uma foto do reator pode ser visualizada na Figura 3.

O tratamento de percolado por meio do sistema de filtração lenta foi constituído por um tanque cilíndrico de polipropileno com altura útil de $1000 \mathrm{~mm}$, diâmetro de $580 \mathrm{~mm}$ e seção circular de $0,26 \mathrm{~m}^{2}$.

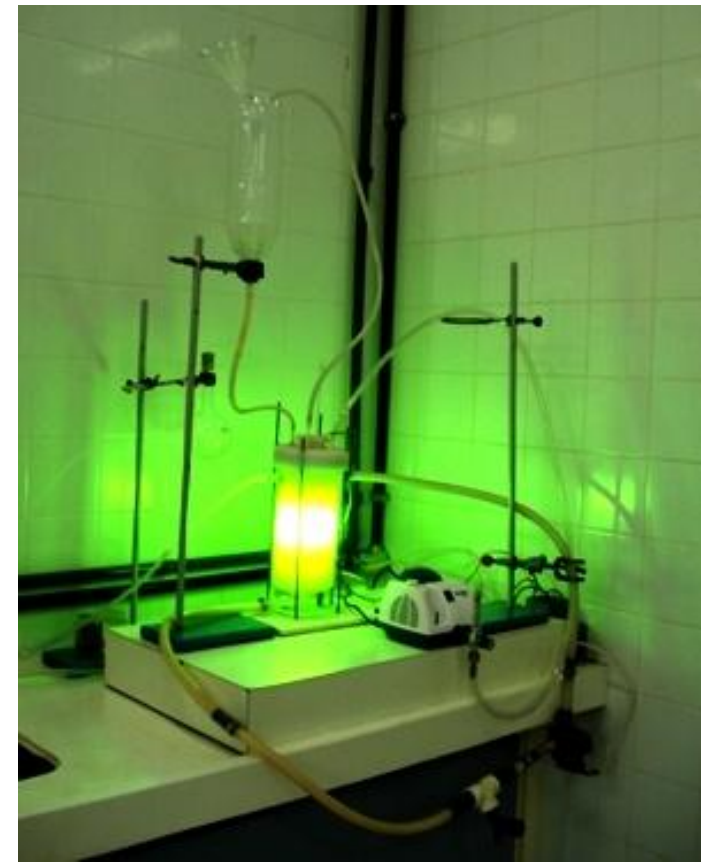

Figura 3: Foto do reator fotocatalítico em funcionamento.

O tempo de detenção hidráulica do percolado dentro do filtro lento foi em média 8 horas. O material filtrante utilizado dentro do filtro foi areia comum utilizada em construção civil e mantas sintéticas não tecidas (Figura 4).

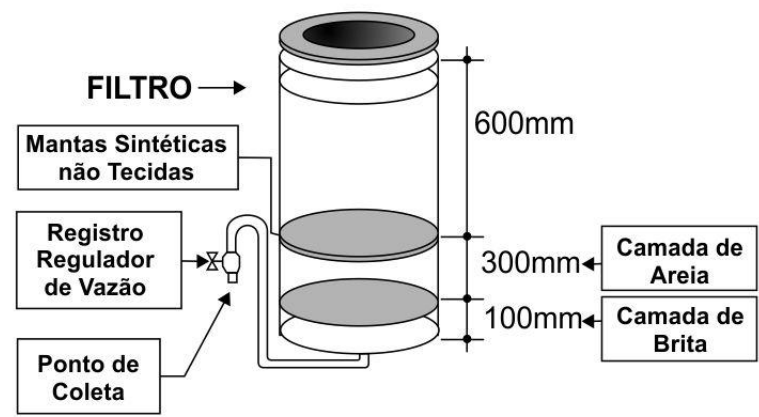

Figura 4: Esquema do filtro lento

O sistema de coleta foi constituído por um tubo de PVC o qual tem origem junto ao sistema de drenagem e segue até $10 \mathrm{~cm}$ acima da camada de areia, evitando assim a ocorrência de pressão negativa e conseqüentemente, acúmulo de ar no interior do meio filtrante, além de garantir a presença constante de percolado no interior do filtro.

Durante os estudos manteve-se o filtro lento com nível constante mediante utilização de uma bóia hidráulica fixa na parte superior e taxa de filtração constante por meio de registro regulador de vazão na parte inferior (após sistema de drenagem). A taxa adotada foi de $3 \mathrm{~m}^{3} / \mathrm{m}^{2} \mathrm{~d}$ sendo monitorada periodicamente através do método volumétrico. (Brito e Paterniani, 2006).

\subsection{Avaliação da eficiência do tratamento fotocatalítico}

$\mathrm{Na}$ avaliação da eficiência do tratamento fotocatalítico do percolado, o peróxido de hidrogênio residual foi determinado de acordo com procedimento 
adaptado de Oliveira et al. (2001), baseado na reação entre peróxido de hidrogênio e o íon vanadato $\left(\mathrm{VO}_{3}{ }^{-}\right)$ em meio ácido. A reação leva à formação de íon peroxovanádio $\left(\mathrm{VO}_{23}{ }^{+}\right)$de coloração avermelhada que absorve fortemente em $446 \mathrm{~nm}$ (Oliveira et al., 2001). A coloração verdadeira do percolado foi determinada de acordo com a absorvância no comprimento de onda máximo na região do visível $(400 \mathrm{~nm})$ utilizando espectrofotômetro DR 2000 da $\mathrm{HACH}$.

\section{RESULTADOS E DISCUSSÃO}

A primeira otimização consistiu em não utilizar radiação, $\mathrm{H}_{2} \mathrm{O}_{2-} 10 \%$, tempo de tratamento de 90 minutos, temperatura de $25^{\circ} \mathrm{C}$, sem vazão de ar. Os resultados estão apresentados na Tabela 1 .

Observou-se uma baixa eficiência na remoção da cor $(26,97 \%)$ em 90 minutos de tratamento, apresentando alta concentração de $\mathrm{H}_{2} \mathrm{O}_{2}$ residual.

Posteriormente realizou-se um novo ensaio utilizando vazão de ar máxima de 15 L. $\min ^{-1}$ (Tabela 2).

\begin{tabular}{|c|c|c|c|c|c|c|}
\hline & Tempo min & $\begin{array}{c}\text { Volume de } \\
\mathrm{H}_{2} \mathrm{O}_{2}(\mathrm{~mL})\end{array}$ & $\begin{array}{c}\text { Absorbância } \\
(400 \text { nm) }\end{array}$ & $\begin{array}{c}\text { Redução de cor } \\
(\%)\end{array}$ & $\begin{array}{c}\text { Absorbância } \\
\mathrm{H}_{2} \mathrm{O}_{2}\end{array}$ & $\begin{array}{l}\text { Conc. } \\
\left(\mathrm{mg.L}^{-1}\right)\end{array}$ \\
\hline $\mathbf{0}$ & $\mathbf{0}$ & 15 & 0,582 & - & - & - \\
\hline 1 & 30 & 10 & 0,441 & 24,22 & 0,355 & 0,213 \\
\hline 2 & 60 & 10 & $\mathbf{0 , 4 3 8}$ & 24,74 & $\mathbf{0 , 3 5 1}$ & 0,209 \\
\hline 3 & 90 & - & 0,425 & 26,97 & 0,412 & 0,253 \\
\hline
\end{tabular}

\begin{tabular}{|c|c|c|c|c|c|c|}
\hline & Tempo min & $\begin{array}{l}\text { Volume de } \\
\mathrm{H}_{2} \mathrm{O}_{2}(\mathrm{~mL})\end{array}$ & $\begin{array}{c}\text { Absorbância } \\
(400 \mathrm{~nm})\end{array}$ & $\begin{array}{c}\text { Redução de cor } \\
(\%)\end{array}$ & $\begin{array}{c}\text { Absorbância } \\
\mathrm{H}_{2} \mathrm{O}_{2}\end{array}$ & $\begin{array}{l}\text { Conc. } \\
\left(\mathrm{mg}^{-1} \mathrm{~L}^{-1}\right)\end{array}$ \\
\hline 0 & 0 & 15 & 0,586 & - & - & - \\
\hline 1 & 30 & 10 & 0,407 & 30,54 & 0,239 & 0,131 \\
\hline 2 & 60 & 10 & 0,429 & 26,80 & 0,243 & 0,134 \\
\hline 3 & 90 & - & 0,414 & 29,35 & 0,240 & 0,132 \\
\hline
\end{tabular}

Observou-se uma baixa eficiência na remoção da cor (29,35\%) em 90 minutos de tratamento, apresentando alta concentração de $\mathrm{H}_{2} \mathrm{O}_{2}$ residual. A diminuição da eficiência do processo com o aumento da concentração de peróxido, podem ser explicados pelo caráter sequestrante (scanveger) de radicais hidroxila (Equações 3 e 4) apresentado pelo peróxido de hidrogênio e ainda pelo processo de recombinação de radicais gerados em excesso (Equação 5).

$$
\begin{array}{ll}
\mathrm{H}_{2} \mathrm{O}_{2}+{ }^{\cdot} \mathrm{OH} & \rightarrow \mathrm{HO}_{2}^{\cdot}+\mathrm{H}_{2} \mathrm{O} \\
\mathrm{HO}_{2}+\mathrm{H}_{2} \mathrm{O} \rightarrow \mathrm{H}_{2} \mathrm{O}+\mathrm{O}_{2} & \text { Eq. (3) } \\
\cdot \mathrm{OH}+{ }^{\cdot} \mathrm{OH} \rightarrow \mathrm{H}_{2} \mathrm{O}_{2} & \text { Eq. (4) }
\end{array}
$$

Diante dos dados alcançados realizou-se uma nova otimização que consistiu em utilizar lâmpada de $400 \mathrm{~W}, \mathrm{H}_{2} \mathrm{O}_{2}-10 \%$, Tempo de $90 \mathrm{~min}$, temperatura de $45^{\circ} \mathrm{C}$, sem vazão de ar e radiação visível.

Os resultados estão apresentados na Tabela

3.

A máxima porcentagem de redução da coloração encontrada foi de $65 \%$ em 90 minutos de tratamento.

O aumento da temperatura e a utilização de radiação na faixa do visível contribuíram para melhoria do tratamento. McGuiga et al. (1998) afirmam que para a temperatura da água acima de $45^{\circ} \mathrm{C}$, há um forte efeito sinérgico entre os mecanismos ópticos e térmicos na inativação de microrganismos. Wei et al. (1994) observaram este efeito em experimentos de desinfecção fotocatalítica com $\mathrm{TiO}_{2}$ onde E.coli foi o microrganismo alvo. A temperatura da água atingiu valores acima de $40^{\circ} \mathrm{C}$ e a fonte de radiação foi à luz solar.

Além disto, a reação do radical hidroxila é mais eficiente porque seu potencial de oxidação $\left(E^{\circ}=\right.$ $+2,8 \mathrm{~V}$ ) é mais elevado que o do peróxido de hidrogênio molecular $\left(E^{\circ}=+1,78 \mathrm{~V}\right)$, podendo promover uma oxidação mais eficiente.

Posteriormente foi realizada uma variação no volume de $\mathrm{H}_{2} \mathrm{O}_{2}$ conforme Tabela 4 .

A porcentagem de redução da coloração encontrada foi de $51,84 \%$ em 90 minutos de tratamento. Demonstrando assim a diminuição da eficiência quando comparado ao ensaio referente à Tabela 3.

Consequentemente foi realizado um novo ensaio utilizando: lâmpada de $400 \mathrm{~W}, \mathrm{H}_{2} \mathrm{O}_{2}-10 \%$, Tempo de $90 \mathrm{~min}$, temperatura de $45^{\circ} \mathrm{C}$, radiação visível através da utilização de um tubo pyrex para abrigo da lâmpada e vazão de ar de $15 \mathrm{~L} \mathrm{~min}^{-1}$. Os resultados encontrados na Tabela 5 mostram que a máxima porcentagem de redução da coloração encontrada foi de $59,96 \%$ inferior aos 65,00\% encontrados no ensaio referente à Tabela 3, sem a utilização de vazão de ar. Importante ressaltar que todos os ensaios resíduos de $\mathrm{H}_{2} \mathrm{O}_{2}$ na ordem de 0,1 mg. L ${ }^{-1}$ (Tabela 5). 
Tabela 3: Redução da coloração do percolado de aterro utilizando tratamento fotoquímico com $\mathrm{H}_{2} \mathrm{O}_{2}$ e radiação visível.

\begin{tabular}{c|c|c|c|c|c|c} 
& $\begin{array}{c}\text { Tempo } \\
(\mathrm{min})\end{array}$ & $\begin{array}{c}\text { Volume de } \\
\mathrm{H}_{2} \mathrm{O}_{2}(\mathrm{~mL})\end{array}$ & $\begin{array}{c}\text { Absorbância } \\
(400 \mathrm{~nm})\end{array}$ & $\begin{array}{c}\text { Redução de cor } \\
(\%)\end{array}$ & $\begin{array}{c}\text { Absorbância } \\
\mathrm{H}_{2} \mathrm{O}_{2}\end{array}$ & $\begin{array}{c}\text { Conc. } \\
\left(\mathbf{m g} \cdot \mathrm{L}^{-1}\right)\end{array}$ \\
\hline 0 & 0 & 15 & 0,581 & - & - & - \\
\hline 1 & 30 & 10 & 0,335 & 42,34 & 0,244 & 0,130 \\
\hline 2 & 60 & 10 & 0,258 & 55,59 & 0,210 & 0,110 \\
\hline 3 & 90 & - & 0,203 & 65,09 & 0,198 & 0,102 \\
\hline
\end{tabular}

Tabela 4: Redução da coloração do percolado de aterro utilizando tratamento fotoquímico com $\mathrm{H}_{2} \mathrm{O}_{2} \mathrm{e}$ radiação visível (volume de $\mathrm{H}_{2} \mathrm{O}_{2} 25 \mathrm{~mL}$ ).

\begin{tabular}{c|c|c|c|c|c|c} 
& $\begin{array}{c}\text { Tempo } \\
(\mathrm{min})\end{array}$ & $\begin{array}{c}\text { Volume de } \mathrm{H}_{2} \mathrm{O}_{2} \\
(\mathrm{~mL})\end{array}$ & $\begin{array}{c}\text { Absorbância } \\
(400 \mathrm{~nm})\end{array}$ & $\begin{array}{c}\text { Redução de cor } \\
(\%)\end{array}$ & $\begin{array}{c}\text { Absorbância } \\
\mathrm{H}_{2} \mathrm{O}_{2}\end{array}$ & $\begin{array}{c}\text { Conc. } \\
\left(\mathrm{mg}^{-1}\right)\end{array}$ \\
\hline 0 & 0 & 15 & 0,569 & - & - & - \\
\hline 1 & 30 & 10 & 0,334 & 41,3 & 0,229 & 0,124 \\
\hline 2 & 60 & - & 0,279 & 50,96 & 0,213 & 0,113 \\
\hline 3 & 90 & - & 0,274 & 51,84 & 0,178 & 0,088 \\
\hline
\end{tabular}

Tabela 5: Redução da coloração do percolado de aterro utilizando tratamento fotoquímico com $\mathrm{H}_{2} \mathrm{O}_{2} \mathrm{e}$ radiação visível (vazão de ar de 15 L.min ${ }^{-1}$ ).

\begin{tabular}{c|c|c|c|c|c|c}
\hline & $\begin{array}{c}\text { Tempo } \\
(\mathrm{min})\end{array}$ & $\begin{array}{c}\text { Volume de } \mathrm{H}_{2} \mathrm{O}_{2} \\
(\mathrm{~mL})\end{array}$ & $\begin{array}{c}\text { Absorbância } \\
(400 \mathrm{~nm})\end{array}$ & $\begin{array}{c}\text { Redução de cor } \\
(\%)\end{array}$ & $\begin{array}{c}\text { Absorbância } \\
\mathrm{H}_{2} \mathrm{O}_{2}\end{array}$ & $\begin{array}{c}\text { Conc. } \\
\left(\mathrm{mg} . \mathrm{L}^{-1}\right)\end{array}$ \\
\hline 0 & 0 & 15 & 0,577 & - & - & - \\
\hline 1 & 30 & 10 & 0,344 & 40,38 & 0,239 & 0,131 \\
\hline 2 & 60 & 10 & 0,278 & 51,81 & 0,205 & 0,107 \\
\hline 3 & 90 & - & 0,231 & 59,96 & 0,197 & 0,101 \\
\hline
\end{tabular}

A porcentagem de redução da coloração encontrada foi de $51,84 \%$ em 90 minutos de tratamento. Demonstrando assim a diminuição da eficiência quando comparado ao ensaio referente à Tabela 3.

Consequentemente foi realizado um novo ensaio utilizando: lâmpada de $400 \mathrm{~W}, \mathrm{H}_{2} \mathrm{O}_{2}-10 \%$, Tempo de 90 min, temperatura de $45^{\circ} \mathrm{C}$, radiação visível através da utilização de um tubo pyrex para abrigo da lâmpada e vazão de ar de 15 L. $\mathrm{min}^{-1}$. Os resultados encontrados na Tabela 5 mostram que a máxima porcentagem de redução da coloração encontrada foi de 59,96\% inferior aos 65,00\% encontrados no ensaio referente à Tabela 3, sem a utilização de vazão de ar. Importante ressaltar que todos os ensaios resíduos de $\mathrm{H}_{2} \mathrm{O}_{2}$ na ordem de 0,1 mg. $\mathrm{L}^{-1}$ (Tabela 5). Este experimento demonstra que para o processo fotoquímico utilizando $\mathrm{H}_{2} \mathrm{O}_{2}$ não é necessária à presença de oxigênio para oxidar a matéria orgânica, isto é devido ao caráter extremamente oxidativo do peróxido de hidrogênio. Além disso, o oxigênio pode diminuir o transporte de massa de radical hidroxila em direção a matéria orgânica.

Com o propósito de verificação dos estudos realizou-se o mesmo ensaio, utilizando $25 \mathrm{~mL}$ de $\mathrm{H}_{2} \mathrm{O}_{2}$ conforme Tabela 6.

A porcentagem de redução da coloração foi inferior (51,58\%) quando utilizados os $25 \mathrm{~mL}$ de $\mathrm{H}_{2} \mathrm{O}_{2}$ referentes à Tabela 5 .

Diante dos resultados alcançados foi possível observar que as melhores condições para o tratamento fotoquímico do percolado de aterro foram:

- $35 \mathrm{~mL}$ de $\mathrm{H}_{2} \mathrm{O}_{2-} 10 \%$,

- tempo de $90 \mathrm{~min}$, temperatura de $45^{\circ} \mathrm{C}$,

- radiação visível através da utilização de um tubo pyrex para abrigo da lâmpada de $400 \mathrm{~W}$,

- $\quad$ sem vazão de ar.

Mediante os dados alcançados realizou-se um ensaio com todas as condições experimentais otimizadas, no entanto, no lugar do $\mathrm{H}_{2} \mathrm{O}_{2}$ acrescentou-se $700 \mathrm{mg} \cdot \mathrm{L}^{-1}$ de $\mathrm{TiO}_{2}$ em um tempo de 180 minutos (Tabela 7).

A porcentagem de redução da coloração (44,8\% em 180 minutos) foi a menor alcançada em todo o estudo, levando-se em consideração o tempo de tratamento. Diante disto resolveu-se faze um planejamento fatorial $3^{3}+3^{2}$, com as seguintes condições experimentais (Tabela 8):

- Volume de $\mathrm{H}_{2} \mathrm{O}_{2-}$ 10\% adicionado: 15,10 e 10 $\mathrm{mL}$ (Tempo: 0' ; 30' e 60');

- Concentração $\mathrm{TiO}_{2} 700 \mathrm{mg} / \mathrm{L}$;

- Temperatura $45^{\circ} \mathrm{C}$;

- Radiação na faixa do visível.

Com os dados obtidos foi possível concluir que com a máxima vazão de ar, máxima temperatura e radiação visível obteve-se uma redução da coloração de $87,1 \%$ com baixa concentração de $\mathrm{H}_{2} \mathrm{O}_{2}$ residual $\left(0,009 \mathrm{mg} \cdot \mathrm{L}^{-1}\right)$, demonstrado a importância da vazão de 
ar quando se utiliza $\mathrm{TiO}_{2}$ já que a fotomineralização só ocorrerá na presença de $\mathrm{O}_{2}$, de acordo com a Equação 6.

$$
\text { semicondutor }
$$

Pol. orgânico $+\mathrm{O}_{2} \rightarrow \mathrm{CO}_{2}+\mathrm{H}_{2} \mathrm{O}+$ ácidos minerais Eq.(6)

Para a manutenção do processo oxidativo durante a absorção de fótons pelo semicondutor, o acúmulo de elétrons na banda de condução, que aumenta a recombinação do par életron/lacuna $(e-/ h+)$, deve ser evitado na superfície do semicondutor. Então o oxigênio age como receptor de életron gerando íon superóxido, com mostrado na Equação 7:

$$
\mathrm{TiO}_{2}(\mathrm{e}-)+\mathrm{O}_{2} \rightarrow \mathrm{TiO}_{2}+\mathrm{O}^{-}
$$

Importante ressaltar também que o uso de peróxidos inorgânicos tem demonstrado excelentes resultados no aumento das taxas de degradação fotocatalíticas de diferentes contaminantes. Em estudos sobre a degradação de chorume por fotocatálise heterogênea com dióxido de titânio constataram aumento na remoção de DQO de $40 \%$ para $60 \%$ quando o peróxido de hidrogênio foi adicionado como receptor de elétrons (Ferreira e Daniel, 2005).

Tabela 6: Redução da coloração do percolado de aterro utilizando tratamento fotoquímico $c o m \mathrm{H}_{2} \mathrm{O}_{2} \mathrm{e}$ radiação visível (volume de $\mathrm{H}_{2} \mathrm{O}_{2} 25 \mathrm{~mL}$ ).

\begin{tabular}{c|c|c|c|c|c|c} 
& $\begin{array}{c}\text { Tempo } \\
(\mathbf{m i n})\end{array}$ & $\begin{array}{c}\text { Volume de } \\
\mathbf{H}_{2} \mathbf{O}_{2}(\mathbf{m L})\end{array}$ & $\begin{array}{c}\text { Absorbância } \\
(\mathbf{4 0 0} \mathbf{~ n m})\end{array}$ & $\begin{array}{c}\text { Redução de cor } \\
(\%)\end{array}$ & $\begin{array}{c}\text { Absorbância } \\
\mathbf{H}_{2} \mathbf{O}_{2}\end{array}$ & $\begin{array}{c}\text { Conc. } \\
\left(\mathbf{m g . L}^{-1}\right)\end{array}$ \\
\hline $\mathbf{0}$ & $\mathbf{0}$ & $\mathbf{1 5}$ & $\mathbf{0 , 5 6 8}$ & - & - & - \\
\hline 1 & $\mathbf{3 0}$ & $\mathbf{1 0}$ & $\mathbf{0 , 3 2 1}$ & $\mathbf{4 3 , 4 8}$ & $\mathbf{0 , 3 6 8}$ & $\mathbf{0 , 2 2 1}$ \\
\hline 2 & $\mathbf{6 0}$ & - & $\mathbf{0 , 2 9 4}$ & $\mathbf{4 8 , 2 3}$ & $\mathbf{0 , 2 4 0}$ & $\mathbf{0 , 1 3 2}$ \\
\hline 3 & $\mathbf{9 0}$ & - & $\mathbf{0 , 2 7 5}$ & $\mathbf{5 1 , 5 8}$ & $\mathbf{0 , 1 8 4}$ & $\mathbf{0 , 0 9 3}$ \\
\hline
\end{tabular}

Tabela 7: Redução da coloração do percolado de aterro utilizando tratamento fotoquímico com $\mathrm{TiO}_{2}$

\begin{tabular}{c|c|c|c} 
& $\begin{array}{c}\text { Tempo } \\
(\mathbf{m i n})\end{array}$ & $\begin{array}{c}\text { Absorbância } \\
(\mathbf{4 0 0} \mathbf{~ n m})\end{array}$ & $\begin{array}{c}\text { Redução de cor } \\
\text { (\%) }\end{array}$ \\
\hline 0 & $\mathbf{0}$ & $\mathbf{0 , 5 9 6}$ & $\mathbf{0}$ \\
\hline 1 & $\mathbf{3 0}$ & $\mathbf{0 , 4 8 8}$ & $\mathbf{1 8 , 1}$ \\
\hline 3 & 90 & $\mathbf{0 , 4 5 6}$ & $\mathbf{2 3 , 5}$ \\
\hline 4 & 120 & $\mathbf{0 , 3 7 3}$ & $\mathbf{3 7 , 4}$ \\
\hline 5 & 150 & $\mathbf{0 , 3 5 3}$ & $\mathbf{4 0 , 8}$ \\
\hline 6 & 180 & $\mathbf{0 , 3 2 9}$ & $\mathbf{4 4 , 8}$ \\
\hline
\end{tabular}

\begin{tabular}{|c|c|c|c|c|}
\hline Variáveis & \multicolumn{2}{|c|}{ Nível (•) } & Nível (0) & Nível (+) \\
\hline Vazão ar & \multicolumn{2}{|c|}{$5,0 \mathrm{~L} / \mathrm{min}$} & 0,0 & $15,0 \mathrm{~L} / \mathrm{min}$ \\
\hline \multicolumn{2}{|c|}{ Tempo Tratamento } & $90 \mathrm{~min}$ & - & $180 \mathrm{~min}$ \\
\hline Experimento & Vazão ar & $\begin{array}{r}\text { Tel } \\
\text { Trata }\end{array}$ & $\begin{array}{c}\text { Redução de cor } \\
(\%)\end{array}$ & $\begin{array}{c}\text { Concentração } \mathrm{H}_{2} \mathrm{O}_{2} \\
\left(\mathrm{mg} \cdot \mathrm{L}^{-1}\right)\end{array}$ \\
\hline 1 & $\bullet$ & & 85,9 & 0,017 \\
\hline 2 & $\bullet$ & & 84,5 & 0,021 \\
\hline 3 & 0 & & 78,8 & 0,015 \\
\hline 4 & 0 & & 86,8 & 0,014 \\
\hline 5 & + & & 85,4 & 0,009 \\
\hline 6 & + & & 87,1 & 0,009 \\
\hline
\end{tabular}

Tabela 8: Redução da coloração do percolado de aterro utilizando tratamento fotoquímico com $\mathrm{H}_{2} \mathrm{O}_{2}$ e $\mathrm{TiO}_{2}$

\section{CONSIDERAÇÕES FINAIS}

O tratamento em estudo apresentou redução da coloração do chorume (87\%), através de condições experimentais otimizadas tais como: volume de peróxido de hidrogênio $35 \mathrm{~mL}$ adicionados ao reator em alíquotas de 15, 10, $10 \mathrm{~mL}$; concentração de $\mathrm{TiO}_{2} 700$ mg. $\mathrm{L}^{-1}$; Temperatura $45^{\circ} \mathrm{C}$, lâmpada de 400 Watts (radiação na faixa do visível) e tempo de tratamento de
180 minutos, sendo que nestas condições o tratamento fotocatalítico não deixou resíduos de peróxido de hidrogênio detectáveis após o tratamento.

\section{AGRADECIMENTOS}

Os autores agradecem ao Conselho Nacional de Pesquisa Científica - (CNPq) pelas bolsas concedidas e suporte técnico. 


\section{REFERÊNCIAS BIBLIOGRÁFICAS}

ASSOCIAÇÃO BRASILEIRA DE NORMAS TÉCNICAS. NBR 10.004. Amostragem de Resíduos, 2004: Dispõe sobre a classificação de resíduos sólidos.

BRITO, N.N.; PATERNIANI, J.E.S. Sistema de Filtração Lenta no Tratamento de Percolado do Aterro Sanitário de Limeira-SP. 77p. Dissertação (Mestrado). Faculdade de Engenharia Agrícola, Universidade de Campinas (UNICAMP), 2006.

BRITO, N.N.; PATERNIANI, J.E.S. Fotocatálise de Percolado de Aterro Sanitário Tratado por Filtração Lenta. 108p. Tese (Doutorado). Faculdade de Engenharia Agrícola, Universidade de Campinas (UNICAMP), 2008.

FERREIRA, I.V.L.; DANIEL, L.A. Fotocatálise Heterogênea com TiO2 aplicada ao tratamento de esgoto sanitário secundário. 160p. Tese (Doutorado). Escola de Engenharia, Universidade Estadual de São Paulo (USP), 2005.

GUIZARD, J.B.R.; PERES, C.R.; BRONZEL, D.; FERREIRA, E.R.; PONTES, F.F.F.; RAFALDINI, M.E. Aterro Sanitário de Limeira. 57 p. Relatório Técnico - Centro Regional Universitário de Espírito Santo do Pinhal, Curso de Engenharia Ambiental, 2004.

MC GUIGAN, K.G.; JOYCE, T.M.; CONROY, R.M.; GILLESPIE, J.B.; ALMORE-MEEGAN, M. Solar desinfection of drinking water contained in transparent plastic bottles: characterizing the bacterial inactivation process. Journal of Applied Microbiology, v.84, p.1138-48, 1998.

OLIVEIRA, M.C.; NOGUEIRA, R.F.P.; NETO, J.A.G.; JARDIM, W.F.; ROHWEDDER, J.J.R. Sistema de injeção em fluxo espectrofotométrico para monitorar peróxido de hidrogênio em processo de fotodegradação por reação foto-fenton. Química Nova, v.24, n.2, p. 188-190, 2001.

PACHECO, J.R.; PERALTA-ZAMORA, P. Integração de processos físico-químicos e oxidativos avançados para remediação de percolado de aterro sanitário (chorume). Engenharia Sanitária e Ambiental, v. 9, n. 4, p. 306-311, 2004.

TEIXEIRA, C.P.A.B; JARDIM, W.F. Processos Oxidativos Avançados - Conceitos Teóricos. Caderno Temático, v.3, Instituto de Química, Universidade Estadual de Campinas (UNICAMP), 2004

WEI, C.; LIN, W-Y.; ZAINA, Z.; WILLIAMS, N.E.; ZHU, K.; KRUZIC, A.P. Bactericidal Activity of TiO2 Photocatalyst in Aqueous Media: Toward a Solar- Assisted Water Disinfection System. Environmental Science and Technology, v. 28, n.5, p.934-938, 1994. 